\title{
Clinical Presentation, Risk Factors, and Treatment Modalities of Hepatocellular Carcinoma: A Single Tertiary Care Center Experience
}

\author{
Abdulrahman A. Aljumah, ${ }^{1,2}$ Hadi Kuriry, ${ }^{3}$ Mohammed AlZunaitan, ${ }^{3}$ \\ Mohammed Al Ghobain, ${ }^{2,3}$ Mohamed Al Muaikeel, ${ }^{2,4}$ Ashwaq Al Olayan, ${ }^{2,5}$ \\ Fahad Azzumeea, ${ }^{2,4}$ Bader Almutairi, ${ }^{2,4}$ Abduljaleel AlAlwan, ${ }^{1,2}$ and Hamdan AlGhamdi ${ }^{1,2}$ \\ ${ }^{1}$ Division of Hepatology, Department of Hepatobiliary Sciences, King Abdulaziz Medical City, \\ Ministry of National Guard Health Affairs, P.O. Box 22490, Riyadh 11426, Saudi Arabia \\ ${ }^{2}$ King Saud bin Abdulaziz University for Health Sciences, P.O. Box 22490, Riyadh 11426, Saudi Arabia \\ ${ }^{3}$ Department of Medicine, King Abdulaziz Medical City, Ministry of National Guard Health Affairs, \\ P.O. Box 22490, Riyadh 11426, Saudi Arabia \\ ${ }^{4}$ Department of Medical Imaging, King Abdulaziz Medical City, Ministry of National Guard Health Affairs, \\ P.O. Box 22490, Riyadh 11426, Saudi Arabia \\ ${ }^{5}$ Department of Adult Medical Oncology, King Abdulaziz Medical City, Ministry of National Guard Health Affairs, \\ P.O. Box 22490, Riyadh 11426, Saudi Arabia
}

Correspondence should be addressed to Abdulrahman A. Aljumah; draljumah@hotmail.com

Received 18 March 2016; Revised 13 June 2016; Accepted 21 June 2016

Academic Editor: Mitsuro Kanda

Copyright (C) 2016 Abdulrahman A. Aljumah et al. This is an open access article distributed under the Creative Commons Attribution License, which permits unrestricted use, distribution, and reproduction in any medium, provided the original work is properly cited.

Objective. To investigate the risk factors, clinical characteristics, treatment modalities, and outcomes in Saudi patients with HCC and propose points for early detection of the disease. Methods. Patients were stratified according to underlying risk factors for the development of HCC. Barcelona Clinic Liver Cancer (BCLC) was used for cancer staging. Treatment was classified into surgical resection/liver transplantation; locoregional ablation therapy; transarterial embolization; systemic chemotherapy; and best supportive care. Results. A total of 235 patients were included. Males had higher tumor size and incidence of portal vein thrombosis. Viral hepatitis was a risk factor in 75.7\%. The most common BCLC stages were B (34.5\%) and A (33.6\%), and the most common radiological presentation was a single nodule of less than $5 \mathrm{~cm}$. Metastases were present in $13.2 \%$. Overall, 77 patients $(32.8 \%)$ underwent a potentially curative treatment as the initial therapy. The most commonly utilized treatment modality was chemoembolization with 113 sessions in 71 patients. The overall median survival was $15.97 \pm 27.18$ months. Conclusion. HCC in Saudi Arabia is associated with high prevalence of HCV. Potentially curative therapies were underutilized in our patients. Cancer stage BCLC-B was the most frequent (34.5\%) followed by BCLC-A (33.6\%). The overall median survival was shorter than other studies.

\section{Introduction}

Hepatocellular carcinoma (HCC) is a primary liver malignancy and one of the most common cancers worldwide and is one of the leading causes of cancer-related death [1-3]. Worldwide, it represents around $90 \%$ of the total primary liver cancer [4].
It is considered as the fifth most common cancer in men $(554,000$ cases, $7.5 \%$ of the total) and the ninth in women $(228,000$ cases, $3.4 \%)$. The prognosis for liver cancer is very poor which has made it globally the second most common cause of death from cancer and was estimated to be accountable for approximately 746,000 deaths in $2012(9.1 \%$ of the total) [5]. 
The highest liver cancer rates are found in East and Southeast Asia and in Middle and Western Africa [6].

This difference in incidence of liver cancer between different geographical regions and countries is mainly attributed to difference in the incidence of underlying risk factors: viral hepatitis, alcohol use, occupational exposure; and nonalcoholic fatty liver disease (NAFLD) [7-12].

HCC is secondary to liver cirrhosis in $80 \%$ of patients and is the main cause of death in liver cirrhosis patients in Europe [13]. Only $30-40 \%$ of patients present with early-stage disease amenable to curative treatments, such as resection or liver transplantation (LT), while others can only undergo local therapies or palliative care [13].

In Saudi Arabia, according to the most recent cancer registry, HCC accounts for $4.8 \%$ of all newly diagnosed cases of all types of cancers. It ranked fourth in males and eighth in females with a male to female ratio of $2.1: 1$ and it accounts for $83 \%$ and $80 \%$ of all liver cancers in males and females, respectively [14]. However it is probable that these numbers were greatly underestimated the accurate incidence, because previously, the national registry depends on a tissue biopsy for confirming the diagnosis of HCC, which was not performed to substantial number of patients with highly suspected diagnosis of HCC and hence they were not counted. This is no longer required for the diagnosis of HCC except for certain cases as per current national and international practice guidelines $[1,4,15]$.

The objective of this study is to investigate the possible risk factors, clinical characteristics, treatment modalities, and outcomes in Saudi patients with HCC and propose points for consideration that may help in the early detection of the disease.

\section{Materials and Methods}

This is a retrospective cohort study of all cases with presumed or confirmed diagnosis of HCC who presented to King Abdulaziz Medical City (KAMC) in Riyadh, Saudi Arabia, between January 2009 and September 2011. The criteria of HCC diagnosis were based on current published local guideline [15] that included (1) diagnosis by liver tumor biopsy and (2) cirrhotic liver, with lesion larger than $1 \mathrm{~cm}$ in diameter, and at least one imaging modality (dynamic CTscan or MR) has confirmed early arterial enhancement and venous washout of the lesion.

Data were collected from the patient's medical records which include patient demographics, comorbidities, date of HCC diagnosis, date of death, and date of last follow-up, presentation of HCC, etiology of underlying liver disease, presence of cirrhosis, tumor number (HCC were classified according to their numbers into solitary lesion, two lesions, and multiple lesions ( 3 or more lesions)), size (according to the maximal tumor diameter and in cases of multinodular tumors, the largest one was measured), presence of portal vein tumor thrombosis (PVTT), presence of vascular invasion and extrahepatic spread, features of portal hypertension including esophageal varices, ascites and splenomegaly, biochemical and hematological parameters, modality of first intervention, and patient survival (measured in months).
The diagnosis of cirrhosis was based on histopathology or combination of imaging features (including hepatic nodularity and ascites), poor synthetic liver function, and findings suggestive of cirrhosis on clinical examination.

Patients were stratified according to underlying risk factors for liver cirrhosis and subsequent development of HCC. Risk factors include HBV, HCV, HBV, and HCV coinfection, alcohol, nonalcoholic fatty liver disease, autoimmune hepatitis (AIH), schistosomiasis, or cryptogenic liver cirrhosis. Cancer staging was based on the recently updated Barcelona Clinic Liver Cancer (BCLC) staging system and treatment strategy [4].

All patients received an initial therapy that was appropriate for their tumor stage and general conditions. The choice of therapy was according to the decision of our institutional tumor board which is a multidisciplinary team that comprises all of the corresponding subspecialties and in view of the local and international guidelines. To properly assess the types of initial therapy, treatment methods were divided into six forms: (1) surgical resection, (2) locoregional ablation therapy, percutaneous ethanol injection (PEI), and radiofrequency ablation (RFA), (3) embolization, transarterial chemoembolization (TACE), and transarterial radioembolization (TARE), (4) systemic chemotherapy and Sorafenib, (5) liver transplantation, and (6) best supportive care. If the patient did not receive any therapy, the initial treatment method was considered as best supportive care.

Posttherapy follow-up as per protocol was performed in all patients and was intended to detect suboptimal response to initial therapy.

In case of suboptimal response to initial therapy, residual or early recurrence, or new primary HCC, patient will be offered the most suitable therapy option sequentially, as second or third intervention to control the tumor and improve patient outcome.

Survival and mortality were investigated by examination of the medical record for the last clinic visit or hospital admission. Survival was defined as the interval between the date of HCC diagnosis and either the date of liver-related death or the last follow-up to 12 September 2012.

2.1. Statistical Analysis. Descriptive statistics were displayed as percentage or continuous data with mean and standard deviation. Fisher's exact test or the Chi square test were used to compare frequencies to assess group differences for categorical variables and Student's $t$-test was used to compare means to assess differences between continuous variables. Comparison of nonparametric data was performed by MannWhitney $U$ test. Survival curves were estimated using the Kaplan-Meier method and the differences in the survival rates between the groups were compared by the log-rank test. A $P$ value of $<0.05$ was considered statistically significant. Statistical Package for Social Sciences (SPSS) version 19.0 (SPSS, Chicago, IL, USA) was used for data analysis.

\section{Results}

Medical records of 253 patients were reviewed. Eighteen patients were excluded because they had metastatic 
TABLE 1: General demographic data of hepatocellular carcinoma (HCC) patients.

\begin{tabular}{lcc}
\hline & Mean \pm SD & $n(\%)$ \\
\hline Age (years) & $65 \pm 10$ & \\
BMI & $27.6 \pm 5.9$ & \\
Gender & & \\
$\quad$ (male : female) & $(2.5: 1)$ \\
Male & $168(71.50 \%)$ \\
Hypertension & $123(52.30 \%)$ \\
Diabetes & $136(57.90 \%)$ \\
Dyslipidemia & $30(12.80 \%)$ \\
Common symptoms & \\
Abdominal pain & $66(28.10 \%)$ \\
Abdominal distension & $35(14.90 \%)$ \\
Anorexia & $30(12.80 \%)$ \\
Fatigue & $27(11.50 \%)$ \\
Weight loss & $20(8.50 \%)$ \\
Jaundice & $18(7.70 \%)$ \\
Underlying cause of liver disease & \\
Viral hepatitis & $178(75.70 \%)$ \\
$\quad$ (i) HCV & $110(46.80 \%)$ \\
$\quad$ (ii) HBV & $62(26.40 \%)$ \\
(iii) HBV + HCV & $6(2.60 \%)$ \\
Nonviral hepatitis & $57(24.30 \%)$ \\
$\quad$ (i) Cryptogenic & $51(21.70 \%)$ \\
$\quad$ (ii) Autoimmune & $3(1.30 \%)$ \\
$\quad$ (iii) Schistosomiasis & $2(0.90 \%)$ \\
$\quad$ (iv) Alcohol & $1(0.40 \%)$ \\
\hline
\end{tabular}

SD: standard deviation; BMI: body mass index; HBV: hepatitis B virus; HCV: hepatitis $\mathrm{C}$ virus.

nonprimary liver tumor and did not meet HCC diagnostic criteria or incomplete medical records. A total of 235 patients were included. Majority were male $(n=168,71.5 \%)$ with proportion of male to female patients of $2.5: 1$. The mean age upon initial diagnosis was $(65 \pm 10)$. Detailed demographic and clinical characteristics are shown in Tables 1 and 2. The male subjects had a significantly higher mean age $(66.1 \pm 10.8$ versus $62.9 \pm 9.8, P=0.028)$, tumor size $(6.5 \pm 5.6$ versus 3.7 $\pm 2.7, P=0.000)$, platelets $(211.5 \pm 142.2$ versus $174 \pm 112.8)$, and incidence of portal vein thrombosis (18.5\% versus $7.5 \%$, $P=0.035)$ but a lower mean body mass index $(26.7 \pm 5.4$ versus $29.7 \pm 6.5, P=0.001)$. Male gender was associated with multifocal tumor (three or more) $(P=0.019)$ and HCC on noncirrhotic liver $(P=0.049)$ compared to female.

Statistically there was no significant difference between males and females in most of other variables, including comorbidities, initial presentation, underlying etiology of liver disease, or liver status as shown in Table 3. The most common stage at presentation was BCLC-B (34.5\%) followed by BCLC-A (33.6\%) (Table 2).

At the time of diagnosis, most HCC patients were symptomatic (52.3\%). Symptomatic cases tend to present commonly with abdominal pain, distension, and anorexia.
TABLE 2: Clinical characteristics of hepatocellular carcinoma (HCC) patients.

\begin{tabular}{|c|c|c|c|}
\hline & Mean \pm SD & & $(n, \%)$ \\
\hline Tumor size $(\mathrm{cm})$ & $5.7+5.1$ & & \\
\hline \multicolumn{4}{|l|}{ Number of tumors } \\
\hline Single & & 117 & $(49.80 \%)$ \\
\hline Two lesions & & 33 & $(14.00 \%)$ \\
\hline Multiple ( $\geq 3$ ) & & 85 & $(36.20 \%)$ \\
\hline \multicolumn{4}{|l|}{ Child-Turcotte-Pugh score } \\
\hline A & & 135 & $(57.40 \%)$ \\
\hline $\mathrm{B}$ & & 75 & $(31.90 \%)$ \\
\hline $\mathrm{C}$ & & 25 & $(10.60 \%)$ \\
\hline Portal vein thrombosis & & 36 & $(15.30 \%)$ \\
\hline Vascular invasion & & 28 & $(11.90 \%)$ \\
\hline Metastasis & & 31 & $(13.20 \%)$ \\
\hline Noncirrhotic liver & & 44 & $(18.70 \%)$ \\
\hline Liver transplant & & 21 & $(8.9 \%)$ \\
\hline MELD & $11+5$ & & \\
\hline Bilirubin, $\mu \mathrm{mol} / \mathrm{L}$ & $41.5 \pm 113$ & & \\
\hline Albumin, g/L & $34 \pm 7$ & & \\
\hline AST, U/L & $96 \pm 103$ & & \\
\hline ALT, U/L & $64 \pm 59$ & & \\
\hline INR & $1.2 \pm 0.4$ & & \\
\hline AFP & $10934.2 \pm 48$ & & \\
\hline Platelets, $\times 10^{9} / \mathrm{L}$ & $201 \pm 135$ & & \\
\hline \multicolumn{4}{|l|}{ BCLC stages } \\
\hline Stage 0 (very early) & & 8 & $(3.4 \%)$ \\
\hline Stage A (early) & & 79 & $(33.6 \%)$ \\
\hline Stage B (intermediate) & & 81 & $(34.5 \%)$ \\
\hline Stage C (advanced) & & 42 & $(17.9 \%)$ \\
\hline Stage D (terminal) & & 25 & $(10.6 \%)$ \\
\hline
\end{tabular}

SD: standard deviation; MELD: model for end-stage liver disease; AFP: alpha-fetoprotein; AST: aspartate aminotransferase; ALT: alanine aminotransferase; INR: international normalized ratio; BCLC: Barcelona Clinic Liver Cancer.

Concerning the underlying etiology of liver disease as HCC risk factors, viral hepatitis was the commonest (75.7\%) followed by cryptogenic liver disease (21.7\%).

In our cohort the most common pattern of radiological presentation of HCC was a single nodule of less than $5 \mathrm{~cm}$ in diameter in 74 cases (31.5\%). Extrahepatic metastases were present in 31 patients (13.2\%) with lung parenchyma metastasis being the most common site 19/31 (61.3\%).

Treatment modalities utilized in our patients at different BCLC stages are shown in Tables 4 and 5. Overall, 77 (32.8\%) of our investigated patients underwent a potentially curative treatment (RFA, PEI, resection, or LT) as the initial therapy. Noncurative therapy (TACE, TARE, and Sorafenib) and best supportive care were offered to 71 patients $(30.2 \%)$ and 87 (37\%) patients as initial therapy, respectively. Among treatment modalities, the most commonly utilized method for tumor control was chemoembolization with 113 sessions in 67 patients. Only 3 cases underwent LT as the first intervention modality. However, most of transplanted patient (18 Patients) 
TABLE 3: Comparison of demographic characteristics, tumor factors, and treatment modalities between male and female patients.

\begin{tabular}{|c|c|c|c|c|c|}
\hline \multirow[b]{2}{*}{ Hypertension } & \multicolumn{2}{|c|}{$\begin{array}{c}\text { Female } n(\%) \\
\text { mean } \pm \mathrm{SD}\end{array}$} & \multicolumn{2}{|c|}{$\begin{array}{l}\text { Male } n(\%) \\
\text { mean } \pm \text { SD }\end{array}$} & \multirow{2}{*}{$\begin{array}{c}P \text { value } \\
0.086\end{array}$} \\
\hline & 41 & $61.20 \%$ & 82 & $48.80 \%$ & \\
\hline Diabetes & 42 & $62.70 \%$ & 94 & $56.00 \%$ & 0.345 \\
\hline \multicolumn{6}{|c|}{ Underlying cause of liver disease } \\
\hline Viral hepatitis & 56 & $83.60 \%$ & 122 & $72.60 \%$ & \multirow{2}{*}{0.077} \\
\hline Nonviral hepatitis & 11 & $16.40 \%$ & 46 & $27.40 \%$ & \\
\hline Symptoms at presentation & 36 & $53.70 \%$ & 87 & $51.80 \%$ & 0.787 \\
\hline Noncirrhotic liver & 7 & $10.40 \%$ & 37 & $22.00 \%$ & 0.049 \\
\hline \multicolumn{6}{|l|}{ Number of tumors } \\
\hline Single & 33 & $49.30 \%$ & 84 & $50.00 \%$ & \multirow{3}{*}{0.019} \\
\hline Two lesions & 15 & $22.40 \%$ & 18 & $10.70 \%$ & \\
\hline Multiple ( $\geq 3$ ) & 19 & $28.40 \%$ & 66 & $39.30 \%$ & \\
\hline Metastasis & 5 & $7.50 \%$ & 26 & $15.50 \%$ & 0.101 \\
\hline Vascular invasion & 7 & $10.40 \%$ & 21 & $12.50 \%$ & 0.661 \\
\hline \multicolumn{6}{|l|}{ Child-Turcotte-Pugh score } \\
\hline A & 31 & $46.30 \%$ & 104 & $61.90 \%$ & \multirow{3}{*}{0.08} \\
\hline B & 26 & $38.80 \%$ & 49 & $29.20 \%$ & \\
\hline $\mathrm{C}$ & 10 & $14.90 \%$ & 15 & $8.90 \%$ & \\
\hline \multicolumn{6}{|l|}{ BCLC stages } \\
\hline Stage 0 & 2 & $3.00 \%$ & 6 & $3.60 \%$ & \multirow{5}{*}{0.011} \\
\hline Stage A & 32 & $47.80 \%$ & 47 & $28.00 \%$ & \\
\hline Stage B & 15 & $22.40 \%$ & 66 & $39.30 \%$ & \\
\hline Stage C & 8 & $11.90 \%$ & 34 & $20.20 \%$ & \\
\hline Stage D & 10 & $14.90 \%$ & 15 & $8.90 \%$ & \\
\hline Portal vein thrombosis & 5 & $7.50 \%$ & 31 & $18.50 \%$ & 0.035 \\
\hline \multicolumn{6}{|l|}{ Initial intervention } \\
\hline Best supportive care & 23 & $34.30 \%$ & 64 & $38.10 \%$ & \multirow{6}{*}{0.013} \\
\hline Chemoembolization & 13 & $19.40 \%$ & 39 & $23.20 \%$ & \\
\hline Ablation therapy & 27 & $40.30 \%$ & 37 & $22.00 \%$ & \\
\hline Sorafenib & 0 & $0.00 \%$ & 20 & $11.90 \%$ & \\
\hline Surgical resection & 3 & $4.50 \%$ & 6 & $3.60 \%$ & \\
\hline Transplant & 1 & $1.50 \%$ & 2 & $1.20 \%$ & \\
\hline AGE & \multicolumn{2}{|c|}{$63 \pm 10$} & \multicolumn{2}{|c|}{$66 \pm 11$} & 0.028 \\
\hline BMI & \multicolumn{2}{|c|}{$29.75 \pm 6.51$} & \multicolumn{2}{|c|}{$26.75 \pm 5.38$} & 0.001 \\
\hline Tumor size $(\mathrm{cm})$ & \multicolumn{2}{|c|}{$3.69 \pm 2.67$} & \multicolumn{2}{|c|}{$6.53 \pm 5.63$} & 0.000 \\
\hline Bilirubin, $\mu \mathrm{mol} / \mathrm{L}$ & \multicolumn{2}{|c|}{$31.1 \pm 29.8$} & \multicolumn{2}{|c|}{$45.7 \pm 132.5$} & 0.181 \\
\hline Albumin, g/L & \multicolumn{2}{|c|}{$31 \pm 7$} & \multicolumn{2}{|c|}{$34 \pm 7$} & 0.002 \\
\hline AST, U/L & & & & & 0.723 \\
\hline ALT, U/L & & & & & 0.204 \\
\hline INR & & & & & 0.018 \\
\hline Creatinine & & & & & 0.997 \\
\hline AFP & & 75 & & & 0.752 \\
\hline Platelets, $\times 10^{9} / \mathrm{L}$ & & & & & 0.035 \\
\hline MELD & & & & & 0.312 \\
\hline
\end{tabular}

SD: standard deviation; BMI: body mass index; MELD: model for end-stage liver disease; AFP: alpha-fetoprotein; AST: aspartate aminotransferase; ALT: alanine aminotransferase; INR: international normalized ratio; BCLC: Barcelona Clinic Liver Cancer. 
TABLE 4: Intervention modalities at different stages.

\begin{tabular}{|c|c|c|c|c|c|}
\hline & $\begin{array}{c}1 s t \\
\text { intervention } \\
(n=235)\end{array}$ & $\begin{array}{c}2 \mathrm{nd} \\
\text { intervention } \\
(n=88)\end{array}$ & $\begin{array}{c}\text { 3rd } \\
\text { intervention } \\
(n=43)\end{array}$ & $\begin{array}{c}\text { 4th } \\
\text { intervention } \\
(n=26)\end{array}$ & $\begin{array}{c}5 \text { th } \\
\text { intervention } \\
(n=13)\end{array}$ \\
\hline TACE & $17.40 \%$ & $35.20 \%$ & $44.20 \%$ & $53.80 \%$ & $53.80 \%$ \\
\hline TARE & $4.30 \%$ & $5.70 \%$ & $7 \%$ & $7.70 \%$ & $0.00 \%$ \\
\hline RFA & $16.20 \%$ & $13.6 \%$ & $11.60 \%$ & $3.80 \%$ & $0.00 \%$ \\
\hline PEI & $11.50 \%$ & $13.6 \%$ & $18.6 \%$ & $19.20 \%$ & $7.70 \%$ \\
\hline Resection & $3.80 \%$ & $2.30 \%$ & $0.00 \%$ & $0.00 \%$ & $0.00 \%$ \\
\hline Transplant & $1.30 \%$ & $13.6 \%$ & $11.60 \%$ & $0.00 \%$ & $7.70 \%$ \\
\hline Sorafenib & $8.50 \%$ & $2.30 \%$ & $7 \%$ & $0.00 \%$ & $23.10 \%$ \\
\hline Best supportive care & $37 \%$ & $13.60 \%$ & $0.00 \%$ & $15.40 \%$ & $7.70 \%$ \\
\hline
\end{tabular}

TACE: transarterial chemoembolization; TARE: transarterial radioembolization; RFA: radiofrequency ablation; PEI: percutaneous ethanol injection.

TABLE 5: Initial intervention modalities per BCLC tumor stage.

\begin{tabular}{lccccc}
\hline \multirow{2}{*}{ Initial intervention } & \multicolumn{5}{c}{ BCLC } \\
& 0 & $\mathrm{~A}$ & $\mathrm{~B}$ & $\mathrm{C}$ & $\mathrm{D}$ \\
\hline PEI & 5 & 20 & 1 & 0 & 1 \\
RFA & 2 & 26 & 5 & 0 & 5 \\
TACE & 0 & 22 & 19 & 0 & 0 \\
TARE & 0 & 2 & 7 & 1 & 0 \\
Sorafenib & 0 & 0 & 11 & 9 & 0 \\
Best supportive care & 1 & 5 & 31 & 32 & 18 \\
Resection & 0 & 3 & 6 & 0 & 0 \\
Transplant & 0 & 1 & 1 & 0 & 1 \\
\hline
\end{tabular}

BCLC: Barcelona Clinic Liver Cancer; TACE: transarterial chemoembolization; TARE: transarterial radioembolization; RFA: radiofrequency ablation; PEI: percutaneous ethanol injection.

received an initial local ablation therapy or chemoembolization and then underwent LT during follow-up as a subsequent intervention. During follow-up, our patients received 2-3 sessions (maximum of 5 sessions) of intervention on average before their tumor becomes under control.

From the gender point of view, 40 (59.7\%) female patients underwent local ablative therapy or embolization as an initial therapy, compared to $76(45 \%)$ male patients. No significant rate difference in relation to gender was observed for patients who have received best supportive care $34.3 \%$ and $38.1 \%$ for female and male, resp.) or LT (1.5\% and $1.20 \%$ for female and male, resp.) as the initial therapeutic modality. Twenty male patients received Sorafenib as initial treatment; however, none of the female patients received so (Table 3). Ultimately, Sorafenib was utilized in 25 males and 3 females during all stages of intervention.

At the time the survival analysis was performed for censored cases, a total of 125 patients (53.2\%) were identified as dead. The cumulative survival rate at 1 and 3 years in male and female groups was $65.5 \%$ and $54.2 \%$ versus 64.2 and $47.8 \%$, respectively. There was no significant difference in overall survival outcome between the two groups $(P=0.926)$ (Figure 1(a)). Similarly, there was no significant difference between cryptogenic and viral hepatitis liver disease as the underlying etiology on the overall survival outcome of
HCC $(P=0.374)$ (Figure $1(\mathrm{~b}))$. However, there was a significant difference in survival outcome based on treatment modalities. The overall survival rate at 1 and 3 years in transplanted patients was $100 \%$. The overall survival rate at 1 year in patients who had surgical resection was $100 \%$, while in patients who have received RFA/PEI, TACE/TARE, and Sorafenib it was $82.8 \%, 78.8 \%$, and $70 \%$, respectively. The three-year survival rate in patients who had surgical resection or Sorafenib was around $55 \%$ while, in patients who have received RFA/PEI and TACE/TARE, the survival rate was $73.4 \%$ and $67.3 \%$, respectively. Patients with best supportive care had the lowest survival rate at 1 and 3 years $37.9 \%$ and $25.3 \%$, respectively. According to BCLC tumor stage, 1-year survival was $100 \%, 81.8 \%, 67.9 \%, 41.5 \%$, and $32 \%$ in stages 0 , $\mathrm{A}, \mathrm{B}, \mathrm{C}$, and $\mathrm{D}$, respectively. While 3-year survival rate was $87.5 \%$ in stage 0 , it was $70.1 \%, 51.2 \%, 31.7 \%$, and $24 \%$ in stages A, B, C, and D, respectively. The overall median survival from diagnosis was $15.97 \pm 27.18$ months (range from 0 to 172.3 months). Mean survival time for males was 26.37 months \pm 34.83 and for females was 22.03 months \pm 22.83 . However, this difference did not reach statistical significance $(P=$ 0.941 ). We performed univariate and multivariate analysis of factors associated with poor survival outcome (Table 6). On multivariate analysis, age, BCLC stages $\mathrm{C}$ and $\mathrm{D}$, multifocal tumor, AST, and ALT correlated with poor outcome.

\section{Discussion}

HCC is an important worldwide health issue, particularly in regions where viral hepatitis prevalence is high. Several reports have identified clearly the magnitude of viral hepatitis in Saudi Arabia [16-19]. However, there are only limited reports on the health burden of HCC and the available modalities of its treatment.

This study revealed that HCC was more prevalent in males, which is in agreement with figures from the previous Saudi Cancer Registry report [14], as well as other local and regional studies [11, 20-24]. The causes for gender differences in the incidence may be explained in part by the differences in exposure to carcinogens like smoking and alcohol and also to the commonly higher rate of viral hepatitis in men [25]. On the other hand, genetic and hormonal factors have been 


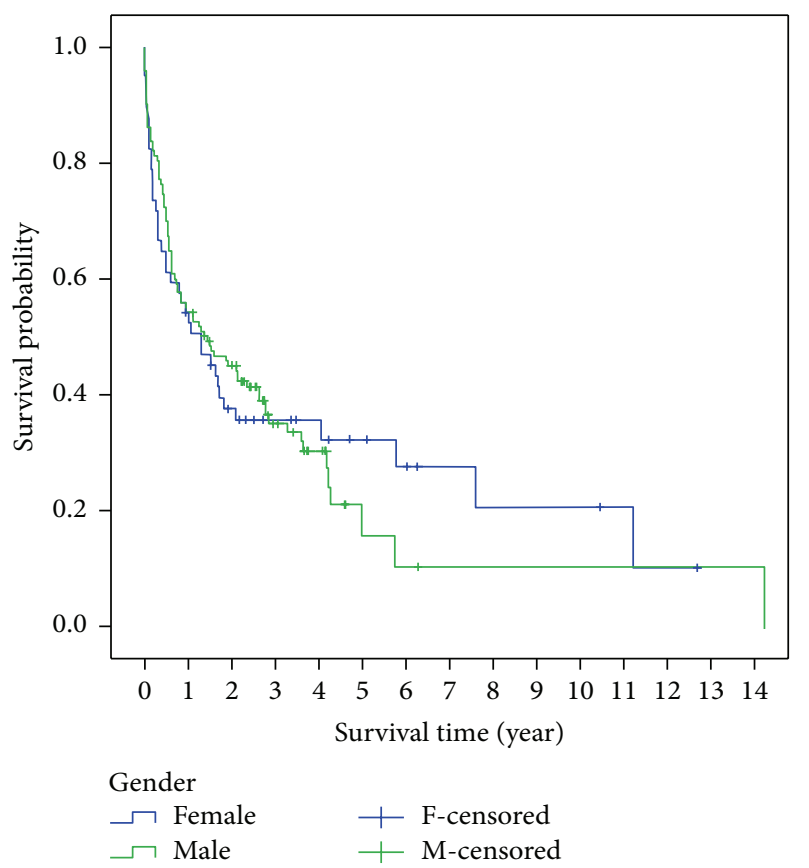

(a)

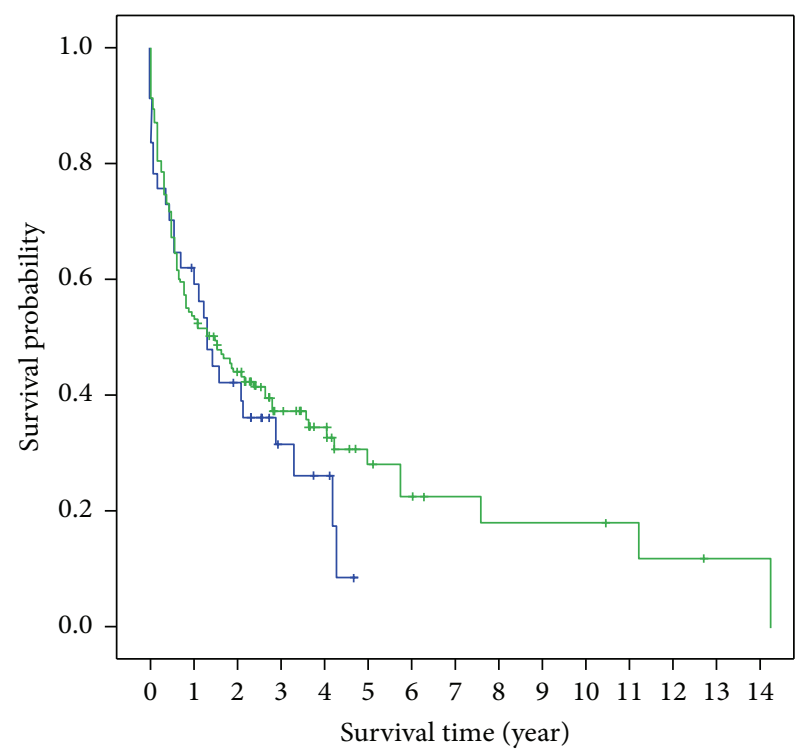

Etiology of liver disease

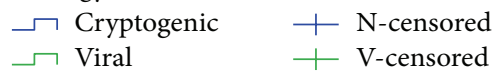

(b)

Figure 1: (a) Cumulative survival rate in patients with hepatocellular carcinoma by gender. (b) Cumulative survival rate in patients with hepatocellular carcinoma by etiology of liver disease.

TABLE 6: Univariate and multivariate cox regression analysis of variables associated with poor survival in HCC patient.

\begin{tabular}{|c|c|c|c|c|c|c|c|c|}
\hline & \multicolumn{4}{|c|}{ Univariate analysis } & \multicolumn{4}{|c|}{ Multivariate analysis } \\
\hline & \multirow{2}{*}{$P$ value } & \multirow{2}{*}{ HR } & \multicolumn{2}{|c|}{$95.0 \% \mathrm{CI}$} & \multirow{2}{*}{$P$ value } & \multirow{2}{*}{$\mathrm{HR}$} & \multicolumn{2}{|c|}{$95.0 \% \mathrm{CI}$} \\
\hline & & & Lower & Upper & & & Lower & Upper \\
\hline Symptomatic cases & 0 & 2.157 & 1.501 & 3.101 & & & & \\
\hline Nonviral hepatitis & 0.022 & 1.617 & 1.073 & 2.437 & & & & \\
\hline Multiple tumor $(\geq 3)$ & 0.00 & 2.996 & 2.019 & 4.446 & 0.000 & 2.679 & 1.577 & 4.552 \\
\hline Metastasis & 0.00 & 5.195 & 3.242 & 8.324 & & & & \\
\hline Vascular invasion & 0.00 & 3.849 & 2.25 & 6.586 & & & & \\
\hline CTP (B) & 0.00 & 2.67 & 1.813 & 3.93 & & & & \\
\hline CTP (C) & 0.00 & 4.31 & 2.531 & 7.339 & & & & \\
\hline $\operatorname{BCLC}(\mathrm{C})$ & 0.00 & 18.776 & 4.382 & 80.445 & 0.044 & 6.283 & 1.052 & 37.545 \\
\hline BCLC (D) & 0.001 & 10.921 & 2.51 & 47.511 & 0.000 & 2.679 & 1.577 & 4.552 \\
\hline Portal vein thrombosis & 0.00 & 4.923 & 3.064 & 7.91 & & & & \\
\hline AGE & 0.00 & 1.039 & 1.019 & 1.06 & 0.000 & 1.048 & 1.023 & 1.074 \\
\hline AST & 0.00 & 1.004 & 1.003 & 1.005 & 0.000 & 1.006 & 1.003 & 1.009 \\
\hline ALT & 0.031 & 1.002 & 1 & 1.005 & 0.001 & 0.993 & 0.989 & 0.997 \\
\hline BMI & 0.024 & 0.964 & 0.934 & 0.995 & & & & \\
\hline Tumor size & 0.00 & 1.078 & 1.045 & 1.111 & & & & \\
\hline Albumin & 0.00 & 0.947 & 0.922 & 0.972 & & & & \\
\hline Creatinine & 0.033 & 1.002 & 1 & 1.004 & & & & \\
\hline Platelets & 0.006 & 1.002 & 1.001 & 1.003 & & & & \\
\hline MELD & 0.00 & 1.069 & 1.045 & 1.094 & & & & \\
\hline
\end{tabular}

CTP: Child-Turcotte-Pugh score; BCLC: Barcelona Clinic Liver Cancer; MELD: model for end-stage liver disease; AST: aspartate aminotransferase; ALT: alanine aminotransferase; BMI: body mass index. 
postulated as risk factors. Estrogen inhibits IL-6 production by Kupffer cells and subsequently decrease cells injuries and proliferation in women while testosterone promotes liver cells in men [26-28].

The peak age of incidence of HCC was found to be in older population with mean age 65 years, which is in line with the recently published data from Saudi Arabia [22] and countries like Italy [29], Japan [30], and Portugal [31]. However, this is fairly different from the average age as reported in the latest US literature, which was between 57 and 59 years [32-34]. In contrast to studies of Alswat et al. [22] and Buch et al. [35], females tend to be younger in age with cirrhotic liver and smaller tumor size than male.

Our data showed that chronic viral hepatitis was the major risk factor contributing to the development of HCC and majority were related to HCV infection, which is similar to recent report [22]. Hepatitis B was the second risk factors for HCC in our study; however, this is quite different from what was reported from developed countries [36-39]. Remarkably, alcohol as a risk factor for underlying liver disease has contributed to only minority of patients $(<1 \%)$.

The clinical presentation of HCC in our patients was not different from those in other studies $[23,40]$, with abdominal pain and abdominal distension being the commonest symptoms. This presentation generally reflects the problem of late presentation.

In our study, the morphological pattern of HCC at the time of diagnosis was unifocal in almost half of the cases, in keeping with other retrospective studies [24, 29, 41], but the contrary was true in the recent report from regional study $[11,22,23,40]$.

With regard to liver function, the majority of our population has preserved liver function, Child-Turcotte-Pugh (CTP) score, class A, which is consistent with other studies [24, 29, $41,42]$. In terms of HCC staging, BCLC combined stages A and B comprise nearly $70 \%$ of cases, similar to Fenoglio et al. [29], but more than reported by Marrero et al. [34].

The development of HCC on underlying liver cirrhosis was noted in $81.3 \%$ of the patients. Singal et al. in a recent meta-analysis found that the rate of presence of underlying cirrhosis between studies was ranging from $32.4 \%$ to $100 \%$, with a pooled rate of $90.9 \%$ [43].

The incidence of extrahepatic metastases has been reported in up to $42 \%$ [44]. Distant metastases were found in $13.2 \%$ of our patients and occurred mainly to the lungs, similar to other studies $[22,45]$. In contrast other retrospective reports have revealed much lower rate of metastases $[29,34,46]$. In our cohort, we attributed this relatively high rate of distant metastases to late presentation, delayed referral from other centers, and the aggressive cancer biology. Portal vein thrombosis is a critical issue that can deteriorate the prognosis of HCC because it can lead to wide dissemination of tumors through the liver and cause a marked deterioration of hepatic function. Portal vein thrombosis was documented in $15.3 \%$ of the cases in our data consistent with low incidence reported from regional and European studies [22, 29, 40], compared to high incidence reports [34, 45-47]. We observed that male patients tend to have higher rate of portal vein thrombosis, similar to Buch et al. [35].
Notably, potentially curative therapies were underutilized and $37 \%$ of our HCC patients received only supportive care for their symptoms, which is higher than some reports [34, 45]. We attributed this to the unsuitable general condition of the patients for advanced therapy, presence of poor prognostic factors, and aggressive behavior of HCC. However our best supportive care rate is considered much lower than most of studies that have reported considerably higher rates of palliative therapy [32, 33, 48-50].

With regard to gender, in our study, a larger percentage of female patients (60\%) underwent local ablative or embolization therapy, compared to male patients and almost similar percentage received best supportive care or LT, which is inconsistent with Devaki et al. result [32]. Exclusively males received Sorafenib as initial treatment while Shah et al. [48] and Zak et al. [49] report no gender difference in intervention.

LT had a limited role in the therapy of HCC in our population. Despite a relatively large number of potentially LT-eligible patients (90 patients; 8 patients in BCLC- 0 and 79 patients in BCLC-A, as shown in (Table 2) in addition to three more patients who were downstaged from BCLC-B and BCLC-C to BCLC-0/A after subsequent interventions), out of those, only 21 patients $(23.3 \%)$ were transplanted, giving a total transplant rate in our cohort of $8.9 \%$, which is less than what is reported by others [32]. This may be due to the fact that the donor pool for LT in Saudi Arabia is limited.

In our population, the overall median survival was shorter than other studies [29, 31-34]. The condition of the patients with regard to the underlying liver disease, tumor burden, and comorbidities could have influenced the prognosis. Other factors like socioeconomic status, access to care, and cultural barriers that were not evaluated in this study could have played a role in the overall outcomes.

There is conflicting published data regarding the impact of gender and etiology on HCC patient survival and prognosis. Our data confirmed that neither gender nor etiology of liver disease has contributed to the survival rate of HCC patients (Figure 1(a)). Similar findings have been obtained in previous studies $[22,29,31,32,49,50]$.

We have made extensive efforts to include larger number of HCC patients with more detailed data. However, our study being hospital-based and from a single tertiary care center has some limitations including possible selection bias as we receive cases from various areas of the country. In addition, we used a retrospective design; therefore, it was possible that many patients were lost to follow-up and we could not collect enough data about their outcome. One further limitation is unavailability of data about treatment modality, indication, complication, and outcome. Despite these limitations, our study highlighted the need for further prospective studies to identify the prognostic factors in HCC patients and to appropriately screen these patients in anticipations of an earlier diagnosis and, therefore, better outcome.

In summary, we believe that our findings are closely representing the actual unique picture of HCC in Saudi Arabia with high prevalence of $\mathrm{HCV}$ and older patients with advanced HCC cases. Significant differences in the receipt of therapy were also observed by gender and underlying 
liver disease. These data suggest the important role of early screening and aggressive management of chronic viral hepatitis particularly hepatitis $\mathrm{C}$, which is potentially possible in the era of the new direct acting antiviral treatment. Further studies are needed to help in describing factors that contribute to low rate of curative therapy, like access to care, surveillance, treatment refusal, lack of specialized care centers, and physician awareness of newly available therapies.

\section{Ethical Approval}

The study was approved by King Abdullah International Medical Research Center (KAIMRC).

\section{Competing Interests}

All authors declare that they have nothing to disclose and have no conflict of interests regarding the publication of this paper.

\section{References}

[1] J. Bruix and M. Sherman, "Management of hepatocellular carcinoma: an update," Hepatology, vol. 53, no. 3, pp. 1020-1022, 2011.

[2] H. B. El-Serag, J. A. Marrero, L. Rudolph, and K. R. Reddy, "Diagnosis and treatment of hepatocellular carcinoma," Gastroenterology, vol. 134, no. 6, pp. 1752-1763, 2008.

[3] M. I. F. Shariff, I. J. Cox, A. I. Gomaa, S. A. Khan, W. Gedroyc, and S. D. Taylor-Robinson, "Hepatocellular carcinoma: current trends in worldwide epidemiology, risk factors, diagnosis and therapeutics," Expert Review of Gastroenterology and Hepatology, vol. 3, no. 4, pp. 353-367, 2009.

[4] "European Association for the Study of the Liver, European Organization for Research and Treatment of Cancer. EASLEORTC clinical practice guidelines: management of hepatocellular carcinoma," Journal of Hepatology, vol. 56, pp. 908-943, 2012.

[5] J. Ferlay, I. Soerjomataram, M. Ervik et al., GLOBOCAN 2012 v1.0, Cancer Incidence and Mortality Worldwide, vol. 11 of IARC Cancer Base no. 11, International Agency for Research on Cancer, Lyon, France, 2013, http://globocan.iarc.fr.

[6] A. Jemal, F. Bray, M. M. Center, J. Ferlay, E. Ward, and D. Forman, "Global cancer statistics," CA: A Cancer Journal for Clinicians, vol. 61, no. 2, pp. 69-90, 2011.

[7] M. F. Yuen, J. L. Hou, and A. Chutaputti, "Hepatocellular carcinoma in the Asia pacific region," Journal of Gastroenterology and Hepatology, vol. 24, no. 3, pp. 346-353, 2009.

[8] J. D. Yang, W. S. Harmsen, S. W. Slettedahl et al., "Factors that affect risk for hepatocellular carcinoma and effects of surveillance," Clinical Gastroenterology and Hepatology, vol. 9, no. 7, pp. 617-623, 2011.

[9] O. Bahri, S. Ezzikouri, N. B. Alaya-Bouafif et al., "First multicenter study for risk factors for hepatocellular carcinoma development in North Africa," World Journal of Hepatology, vol. 3, no. 1, pp. 24-30, 2011.

[10] E. A. Ayoola and M. O. Gadour, "Hepatocellular carcinoma in Saudi Arabia: role of hepatitis B and C infection," Journal of Gastroenterology and Hepatology, vol. 19, no. 6, pp. 665-669, 2004.
[11] A.-R. El-Zayadi, H. M. Badran, E. M. F. Barakat et al., "Hepatocellular carcinoma in Egypt: a single center study over a decade," World Journal of Gastroenterology, vol. 11, no. 33, pp. 5193-5198, 2005.

[12] R. Dhanasekaran, A. Limaye, and R. Cabrera, "Hepatocellular carcinoma: current trends in worldwide epidemiology, risk factors, diagnosis, and therapeutics," Journal of Hepatic Medicine, vol. 4, pp. 19-37, 2012.

[13] J. M. Llovet, A. Burroughs, and J. Bruix, "Hepatocellular carcinoma," The Lancet, vol. 362, no. 9399, pp. 1907-1917, 2003.

[14] Cancer Incidence Report in Saudi Arabia, Saudi Cancer Registry, 2010, http://www.chs.gov.sa/Ar/mediacenter/NewsLetter/ 2010\%20Report\%20(1).pdf.

[15] A. A. Abdo, M. Hassanain, A. R. AlJumah et al., "Saudi guidelines for the diagnosis and management of hepatocellular carcinoma: technical review and practice guidelines," Annals of Saudi Medicine, vol. 32, no. 2, pp. 174-199, 2012.

[16] Z. A. Memish, B. A. Knawy, and A. El-Saed, "Incidence trends of viral hepatitis A, B, and C seropositivity over eight years of surveillance in Saudi Arabia," International Journal of Infectious Diseases, vol. 14, no. 2, pp. el15-e120, 2010.

[17] F. Z. Al-Faleh, M. Al-Jeffri, S. Ramia et al., "Seroepidemiology of Hepatitis B virus infection in Saudi children 8 years after a mass hepatitis B vaccination programme," Journal of Infection, vol. 38, no. 3, pp. 167-170, 1999.

[18] A. A. Abdo, A. M. Abdou, U. S. Akarca et al., "A review of chronic hepatitis B epidemiology and management issues in selected countries in the Middle East," Journal of Viral Hepatitis, vol. 19, no. 1, pp. 9-22, 2012.

[19] T. A. Madani, "Hepatitis C virus infections reported in Saudi Arabia over 11 years of surveillance," Annals of Saudi Medicine, vol. 27, no. 3, pp. 191-194, 2007.

[20] B. Fashir, V. Sivasubramaniam, S. Al-Momen, and H. Assaf, "Hepatic tumors in a Saudi patients population," Saudi Journal of Gastroenterology, vol. 2, pp. 87-90, 1996.

[21] M. Kingston, M. A. Ali, and D. Lewall, "Hepatic tumors in Saudi Arabia. A practical approach to diagnosis," Cancer, vol. 55, no. 7, pp. $1579-1585,1985$.

[22] K. A. Alswat, F. M. Sanai, M. Altuwaijri et al., "Clinical characteristics of patients with hepatocellular carcinoma in a middle eastern population," Hepatitis Monthly, vol. 13, no. 5, article e7612, 2013.

[23] H. Jaka, S. E. Mshana, P. F. Rambau, N. Masalu, P. L. Chalya, and S. E. Kalluvya, "Hepatocellular carcinoma: clinicopathological profile and challenges of management in a resource-limited setting," World Journal of Surgical Oncology, vol. 12, article 246, 2014.

[24] B. Özer, E. Serin, U. Yilmaz et al., "Clinicopathologic features and risk factors for hepatocellular carcinoma: results from a single center in southern Turkey," Turkish Journal of Gastroenterology, vol. 14, no. 2, pp. 85-90, 2003.

[25] J. Wands, "Hepatocellular carcinoma and sex," The New England Journal of Medicine, vol. 357, no. 19, pp. 1974-1976, 2007.

[26] M.-W. Yu, H.-C. Chang, S.-C. Chang et al., "Role of reproductive factors in hepatocellular carcinoma: impact on hepatitis B- and C-related risk," Hepatology, vol. 38, no. 6, pp. 1393-1400, 2003.

[27] W. E. Naugler, T. Sakurai, S. Kim et al., "Gender disparity in liver cancer due to sex differences in MyD88-dependent IL-6 production," Science, vol. 317, no. 5834, pp. 121-124, 2007.

[28] M.-W. Yu and C.-J. Chen, "Elevated serum testosterone levels and risk of hepatocellular carcinoma," Cancer Research, vol. 53, no. 4, pp. 790-794, 1993. 
[29] L. Fenoglio, C. Serraino, E. Castagna et al., "Epidemiology, clinical-treatment patterns and outcome in 256 hepatocellular carcinoma cases," World Journal of Gastroenterology, vol. 19, no. 21, pp. 3207-3216, 2013.

[30] M. Omata, Y. Dan, B. Daniele et al., "Clinical features, etiology, and survival of hepatocellular carcinoma among different countries," Journal of Gastroenterology and Hepatology, vol. 17, no. 1, pp. S40-S49, 2002.

[31] A. S. M. Martins, H. Cortez-Pinto, P. Marques-Vidal et al., "Treatment and prognostic factors in patients with hepatocellular carcinoma," Liver International, vol. 26, no. 6, pp. 680-687, 2006.

[32] P. Devaki, R. J. Wong, V. Marupakula et al., "Approximately one-half of patients with early-stage hepatocellular carcinoma meeting Milan criteria did not receive local tumor destructive or curative surgery in the post-MELD exception era," Cancer, vol. 120, no. 11, pp. 1725-1732, 2014.

[33] P. R. Atla, M. Y. Sheikh, R. Mascarenhas, J. Choudhury, and P. Mills, "Survival of patients with hepatocellular carcinoma in the San Joaquin Valley: a comparison with California Cancer Registry data," Annals of Gastroenterology, vol. 25, no. 2, pp. 138146, 2012.

[34] J. A. Marrero, R. J. Fontana, A. Barrat et al., "Prognosis of hepatocellular carcinoma: comparison of 7 staging systems in an American cohort," Hepatology, vol. 41, no. 4, pp. 707-716, 2005.

[35] S. C. Buch, V. Kondragunta, R. A. Branch, and B. I. Carr, "Gender-based outcomes differences in unresectable hepatocellular carcinoma," Hepatology International, vol. 2, no. 1, pp. 95$101,2008$.

[36] HB. El-Serag, Epidemiology of viral hepatitis and hepatocellular carcinoma. Gastroenterology, 1264 -1273, 142, 2012.

[37] T. Stroffolini, "Etiological factor of hepatocellular carcinoma in Italy," Minerva Gastroenterologica e Dietologica, vol. 51, no. 1, pp. $1-5,2005$.

[38] H. Nordenstedt, D. L. White, and H. B. El-Serag, "The changing pattern of epidemiology in hepatocellular carcinoma," Digestive and Liver Disease, vol. 42, supplement 3, pp. S206-S214, 2010.

[39] A. P. Venook, C. Papandreou, J. Furuse, and L. L. de Guevara, "The incidence and epidemiology of hepatocellular carcinoma: a global and regional perspective," The Oncologist, vol. 15, supplement 4, pp. 5-13, 2010.

[40] A. K. Salem, A. Abdulrab, Y. Alfakeh, and A. Aown, "Hepatocellular carcinoma in Yemeni patients: a single centre experience over an 8-year period," Eastern Mediterranean Health Journal, vol. 18, no. 7, pp. 693-699, 2012.

[41] G. N'Kontchou, A. Mahamoudi, M. Aout et al., "Radiofrequency ablation of hepatocellular carcinoma: long-term results and prognostic factors in 235 Western patients with cirrhosis," Hepatology, vol. 50, no. 5, pp. 1475-1483, 2009.

[42] M. A. Yusuf, F. Badar, F. Meerza et al., "Survival from hepatocellular carcinoma at a cancer hospital in Pakistan," Asian Pacific Journal of Cancer Prevention, vol. 8, no. 2, pp. 272-274, 2007.

[43] A. G. Singal, A. Pillai, and J. Tiro, "Early detection, curative treatment, and survival rates for hepatocellular carcinoma surveillance in patients with cirrhosis: a meta-analysis," PLoS Medicine, vol. 11, no. 4, Article ID e1001624, 2014.

[44] M.-S. Si, F. Amersi, S. R. Golish et al., "Prevalence of metastases in hepatocellular carcinoma: risk factors and impact on survival," American Surgeon, vol. 69, no. 10, pp. 879-885, 2003.
[45] Y. J. Kim, B. K. Jang, E. S. Kim et al., "Hepatocellular carcinoma in the elderly: clinical characteristics, treatment, survival analysis in Korean patients older than 70 years," Journal of Korean Medical Science, vol. 27, no. 10, pp. 1147-1154, 2012.

[46] T. F. Greten, F. Papendorf, J. S. Bleck et al., "Survival rate in patients with hepatocellular carcinoma: a retrospective analysis of 389 patients," British Journal of Cancer, vol. 92, no. 10, pp. 1862-1868, 2005.

[47] C. Yaghi, A. L. Sharara, P. Rassam et al., "Hepatocellular carcinoma in Lebanon: etiology and prognostic factors associated with short-term survival," World Journal of Gastroenterology, vol. 12, no. 22, pp. 3575-3580, 2006.

[48] S. A. Shah, J. K. Smith, Y. Li, S. C. Ng, J. E. Carroll, and J. F. Tseng, "Underutilization of therapy for hepatocellular carcinoma in the medicare population," Cancer, vol. 117, no. 5, pp. 1019-1026, 2011.

[49] Y. Zak, K. F. Rhoads, and B. C. Visser, "Predictors of surgical intervention for hepatocellular carcinoma: race, socioeconomic status, and hospital type," Archives of Surgery, vol. 146, no. 7, pp. 778-784, 2011.

[50] F. Trevisani, G. Magini, V. Santi et al., "Impact of etiology of cirrhosis on the survival of patients diagnosed with hepatocellular carcinoma during surveillance," American Journal of Gastroenterology, vol. 102, no. 5, pp. 1022-1031, 2007. 


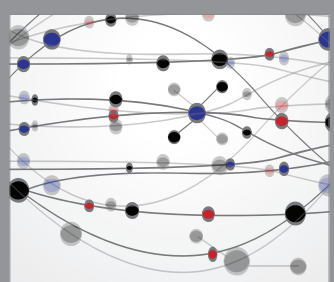

The Scientific World Journal
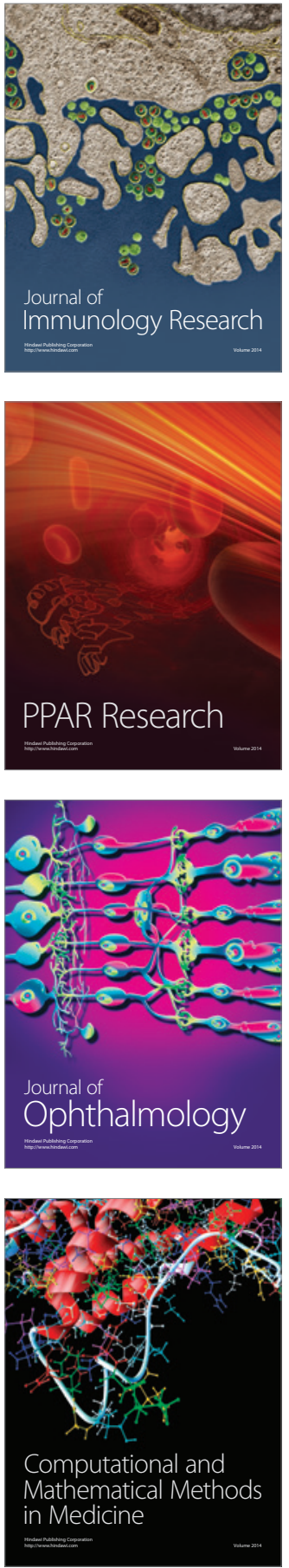

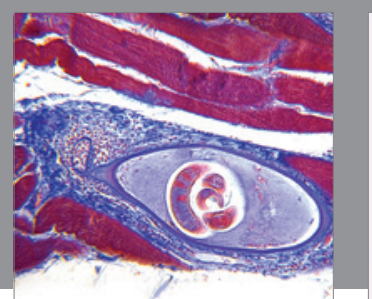

Gastroenterology Research and Practice

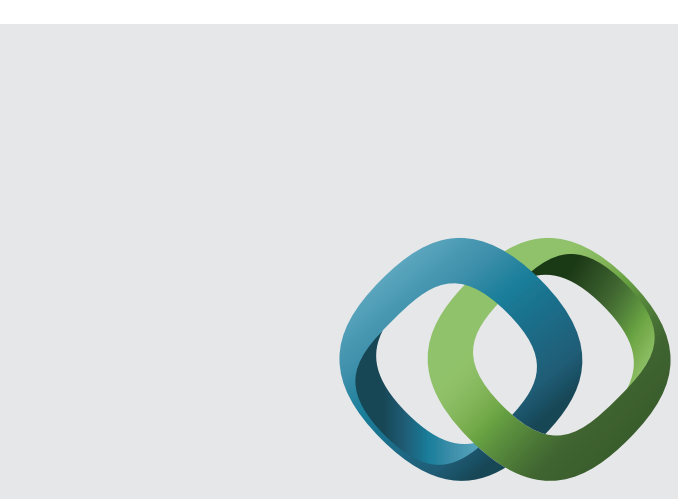

\section{Hindawi}

Submit your manuscripts at

http://www.hindawi.com
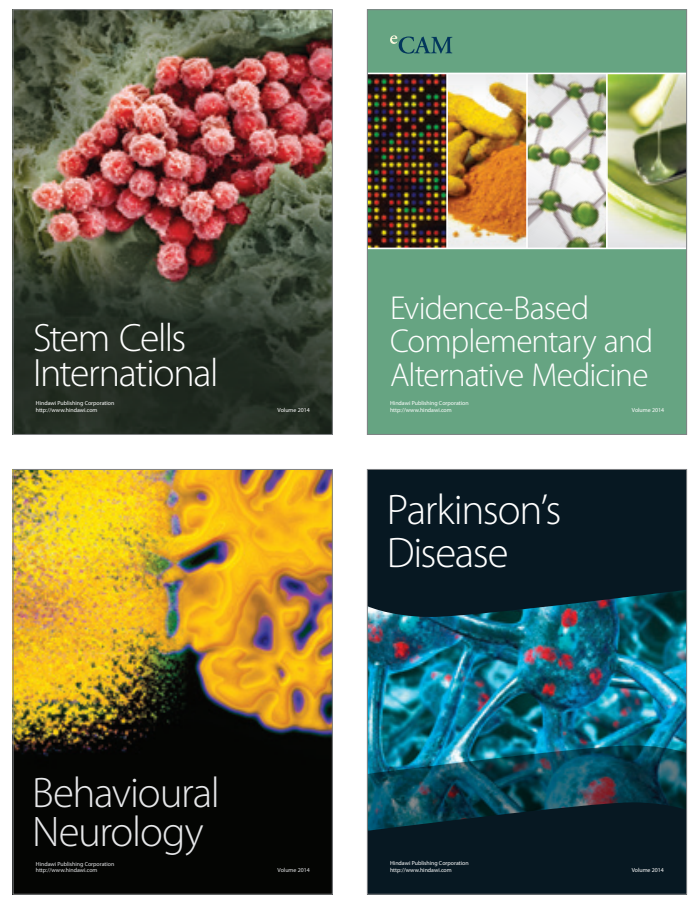
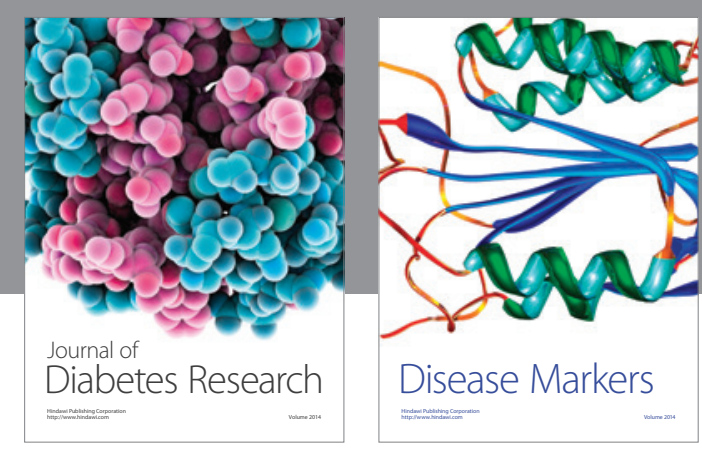

Disease Markers
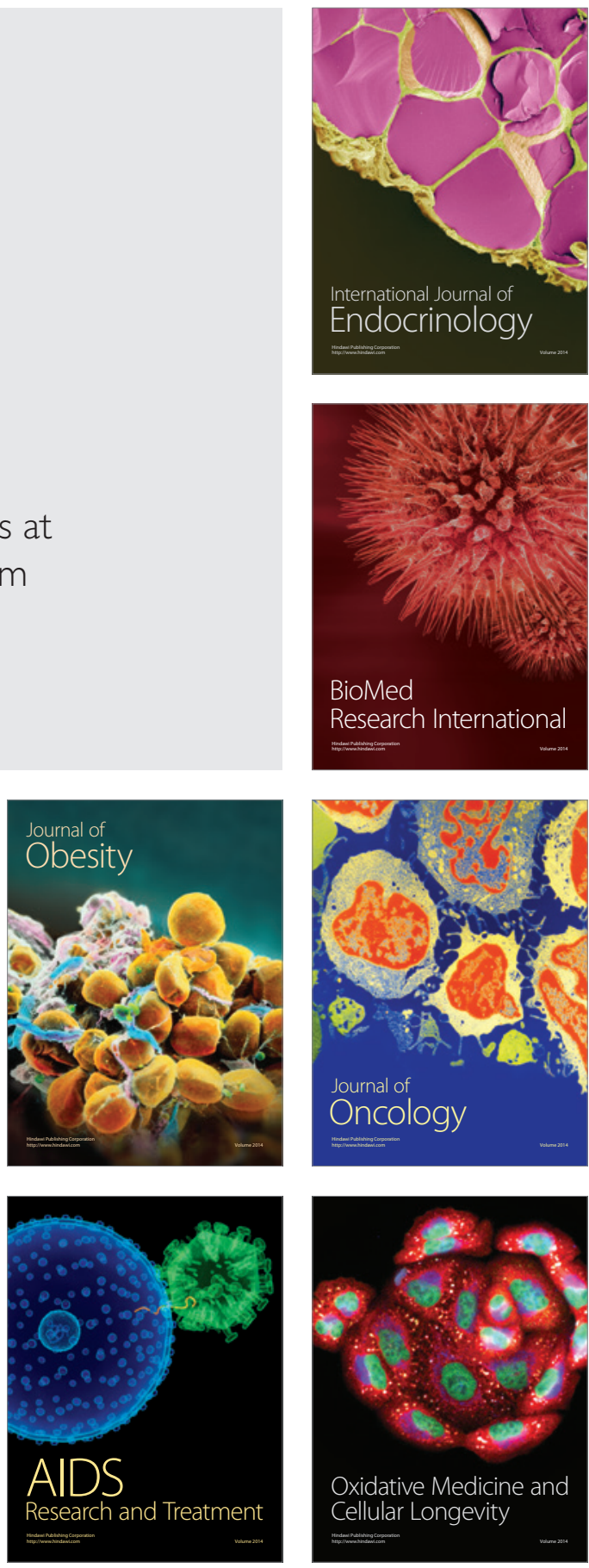